\title{
Perceptions regarding the quality of group interactions during brainstorming session of problem based learning (PBL) at Melaka Manipal Medical College (Manipal Campus), India
}

\author{
Vasudha Devi ${ }^{1}$, Vinod Pallath ${ }^{2}$, Benny Lim ${ }^{3}$, Chia Wue3, Cheng Kok Mun ${ }^{3}$, Jacinta Agnes \\ Adward $^{3}$, Law De Zhi ${ }^{3}$ \\ ${ }^{1}$ Associate Professor and Head of Pharmacology, ${ }^{2}$ Assistance Professor of Microbiology, ${ }^{3}$ Students of Bachelor \\ of Medicine and Bachelor of Surgery (MBBS), Melaka Manipal Medical College (Manipal Campus), Manipal \\ University, Manipal, India.
}

\section{ARTICLE INFO}

Received

Accepted

: 23/01/2012

Published

: 07/05/2012

: 01/12/2012

\section{KEYWORD}

Problem-based learning

Medical students

Medicine

Interaction

Perception

\section{ABSTRACT}

Objective: In PBL, interaction in tutorial group plays a role in stimulating student learning. However, quality of group interactions need not be always in a desired level which will later affect group success. Hence the aim of this study was to ascertain the quality of group interactions during PBL sessions. Method: In this prospective, observational study, to obtain the perceptions of students and faculty $(n=32)$, a preformed questionnaire was used. Students from $1^{\text {st }}(n=129)$ and $2^{\text {nd }}$ year $(n=106)$ of Bachelors of Medicine and Bachelors of Surgery (MBBS) program and faculty were asked to respond in the questionnaire during a PBL brain-storming session. To explore reasons for adequate and inadequate interactions, focus group (n $=10$ ) discussions were conducted. Results: There was no difference in perceptions regarding interactions between $1^{\text {st }}$ year and $2^{\text {nd }}$ year students. But there was significant difference between students and faculty perceptions regarding posing critical questions $(p=0.002)$, counter argument $(\mathrm{p}=0.001)$ and handling conflicts. Factors that drove interactions were the prior knowledge, assessment and motivation and the hindering factor was case scenarios which were not designed based on students' prior knowledge. Conclusion: Faculty expectations regarding PBL group interaction is different from the students' understanding of PBL interaction. This study helps us to bridge the gap between the faculty expectations and students' performance by orienting them regarding an ideal PBL interaction.

(C) Medical Education Department, School of Medical Sciences, Universiti Sains Malaysia. All rights reserved.

CORRESPONDING AUTHOR: Dr. Vasudha Devi, Associate professor and Head Department of Pharmacology, Melaka Manipal Medical College, Manipal University, Manipal, India 576104.

Tel: 918971494100, Fax: 918202571905, Email: v21devi@gmail.com 


\section{Introduction}

Collaborative learning situations like problem based learning (PBL) assign students an active and constructive role in their own learning [1]. In collaborative learning, construction of knowledge takes place through cognitive interaction processes, i.e. elaboration or coconstruction processes (or both) [2-4]. The interactions that are manifestation of elaboration and /or co-construction processes are called as learning-oriented interactions. Elaboration is the process of considering a piece of knowledge in a richer and wider context [5], whereas coconstruction is a special case of an elaboration, a collaborative elaboration where students develop shared understanding of the problem by interacting with each other [3]. The lack of elaboration is an important contributor to the students' perception of an unproductive tutorial group [6].

Problem-based learning enhances higher-order thinking skills, such as applying, evaluation and synthesizing knowledge [7]. Brainstorming phase of PBL is an effective procedure to activate knowledge and to elaborate on knowledge and acquire comprehension of relevant new information [4]. In this phase learning takes place through interactions and elaborations $[4,8]$. There is a positive relationship between interactions and tutorial group productivity as well as a positive relationship between interactions and elaborations [9, 10]. However, when the interactions are not at the desired level $[9,11]$ and in pseudo interactions [12] synthesizing the knowledge by elaborations does not take place. Hence the low quality interactions may be responsible for unsuccessful tutorial group [11]. When quality of interaction is measured it can be used for giving feedback on tutorial group and students' performance and also to train students on good quality interactions.

The research question in the present study was to find out whether the quality of students' interactions during brainstorming session of PBL at Melaka Manipal Medical College (MMMC), (Manipal Campus), India was reasonable or not.
In this study researchers' intention was to ascertain the quality of group interactions during PBL by two ways: (1). Assessing the perceptions of students and faculty on quality of group interactions during brainstorming session at MMMC. (2). Comparing students' and faculty perceptions on quality of group interactions. Comparison of students' and faculty perception is important as faculty perceptions are the indicators of faculty expectations. Hence it was hypothesised that there could be discrepancies in students' and faculty perceptions on quality of group interactions.

\section{Method}

\section{Educational context}

In our medical program, students admitted are initially placed in Manipal, India (Phase I of the program) and after successfully completing two and a half years of pre-clinical training, they return to Melaka, Malaysia for the clinical training (Phase II of the program). MMMC follows a hybrid curriculum where $30 \%$ of the curriculum is covered through PBL, and PBL sessions are conducted modelled on the Maastricht ‘seven jump’ approach.

\section{Questionnaires and subjects}

To assess the quality of PBL group interaction, a pre-formed questionnaire (scale 1 to 5 ) designed by Visschers-Pleijers et al, 2005 [13] was used. The questionnaire had 11 items belonging to three different dimensions to distinguish three types of learning oriented interactions: exploratory question, cumulative reasoning and handling conflicts [13].The questionnaire was given to $I^{\text {st }}(n=129)$ and $2^{\text {nd }}$ year $(n=106)$ medical students during one of the PBL brainstorming sessions. The same questionnaire was also given to MMMC faculty.

The questionnaires were made anonymous before giving and the subjects were asked to indicate their responses in 5 point Likert scale.

To identify the reasons for adequate and inadequate interactions during the brainstorming session, focus group discussions $(\mathrm{n}=10)$ were 
conducted with 6 groups of students each from both the batches. The questions to be used during focus group discussion were developed after extensive literature review $[2,4,6,8-13]$. Content validity of the questionnaire was assessed by taking the opinions from the experts in medical education. The present cross sectional study was approved by the Institutional Research Committee of MMMC. Informed consent was obtained from the subjects before responding in the questionnaire.

\section{Analysis}

Statistical analysis was performed using the Statistical Package for the Social Sciences (SPSS) version 11.5. The categorical variables were described as median and interquartile range. Comparison of responses between the groups was done using Kruskal-Wallis test and Mann-Whitney test for pair-wise comparison. Comparison of factors within the groups was done using Friedman test followed by Wilcoxon Signed Rank Test. p value of $<0.017$ was considered as statistically significant.

The students response to different questions asked during focus group discussion were tabulated in the decreasing order of frequency of their appearance. Later two authors independently grouped the responses into three categories. Finally the categories and responses were finalized by consensus among authors.

\section{Result}

Table 1 shows the average median score for perception regarding occurrence of each item in the questionnaire in $1^{\text {st }}$ year, $2^{\text {nd }}$ year student groups and faculty groups. The cumulative average score of the three factors in different groups is shown in Figure 1. Table 2 shows students' responses obtained during focus group discussion.

The response rate was $100 \%$ in faculty and students groups. The cumulative average of factor handling conflict had the highest median score of $16(13.3,16$ : scale $1-5)$ in $2^{\text {nd }}$ year batch compared to exploratory questions $[15(14,16)]$ and cumulative reasoning $[15(13,17)]$ factors. The factor cumulative reasoning scored highest $[16(14.5,16)]$ on occurrence in $1^{\text {st }}$ year batch and handling conflict factor scored lowest [14.7 $(13.3,16)]$.

In faculty group handling conflict factor scored lowest on occurrence [13.3 $(9.66,16)]$ (Figure 1). At item level, there was no significant difference in the perception regarding occurrence of different types of interactions between $1^{\text {st }}$ year and $2^{\text {nd }}$ year student groups. There was significant difference in the opinion regarding the occurrence of item 2 between $1^{\text {st }}$ year students' and faculty group $(\mathrm{p}=0.002)$. There was also significant differences between student groups and faculty regarding item $11\left(2^{\text {nd }}\right.$ year student vs faculty; 0.001 and $1^{\text {st }}$ year student vs faculty; 0.001). More number of students agreed that critical questions were asked and counter arguments happened during group discussion but less number of faculties agreed for that (Table 1).

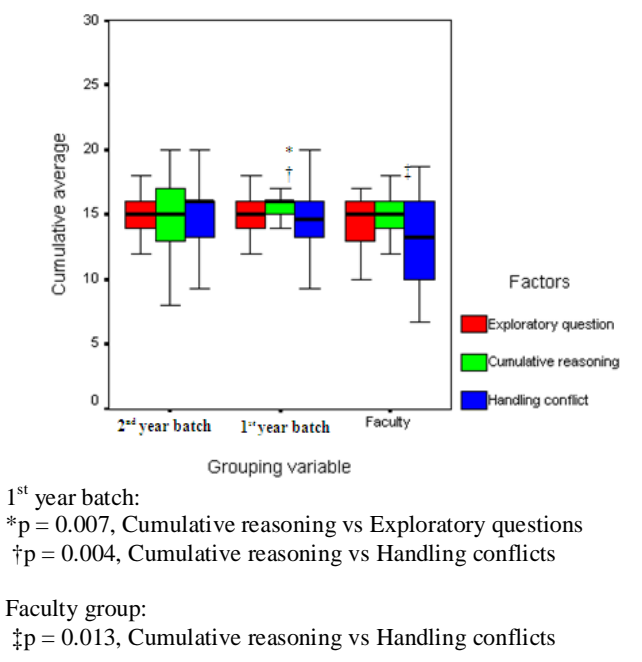

Figure 1: Comparison of cumulative average score on each factor within students' and faculty groups.

Factor level analysis yielded significant differences in the opinion regarding occurrence of handling conflict factor between student groups and faculty (Figure 2). Faculty felt that interactions related to handling conflict occurred less frequently.

According to students' opinion the main factors that drove interaction were the assessment and motivation. The main hindering factor for the 
group interaction was the case scenarios which were not designed based on students' prior knowledge.

Table 1: Students' and faculty perceptions (median with inter-quartile range) regarding group interactions

\begin{tabular}{|c|c|c|c|}
\hline Item number & $\begin{array}{l}1^{\text {st }} \text { year } \\
\text { batch }\end{array}$ & $\begin{array}{l}2^{\text {nd }} \text { year } \\
\text { batch }\end{array}$ & Faculty \\
\hline $\begin{array}{l}\text { 1. Students posed adequate questions to each other in order to understand } \\
\text { the learning content (e.g. questions on meaning of concepts, differences, } \\
\text { reasons and concrete examples) }\end{array}$ & $3(4,4)$ & $3(4,4)$ & $4(3,4)$ \\
\hline $\begin{array}{l}\text { 2. What group members said was checked by asking each other critical } \\
\text { questions }\end{array}$ & $3(4,4)$ & $3(4,4)$ & $3(3,4)$ \\
\hline $\begin{array}{l}\text { 3. A group member who was formulating an explanation concerning the } \\
\text { problem asked in between times whether his/her explanation was right }\end{array}$ & $3(4,4)$ & $3(4,4)$ & $4(4,4)$ \\
\hline $\begin{array}{l}\text { 4. One explanation did not suffice for the group members; alternative } \\
\text { explanations were also mentioned }\end{array}$ & $3(4,4)$ & $3(4,4)$ & $4(3,4)$ \\
\hline 5. Group members elaborated on each other’s arguments & $4(4,4)$ & $4(4,4)$ & $4(3,4)$ \\
\hline 6. When someone argued something, then that statement was motivated & $4(3,4)$ & $4(3,4)$ & $4(3,4)$ \\
\hline $\begin{array}{l}\text { 7. Explanations of group members were completed with explanations of } \\
\text { other group members }\end{array}$ & $4(3,4)$ & $4(3,4)$ & $4(3.25,4)$ \\
\hline $\begin{array}{l}\text { 8. Students drew conclusions from the information that was discussed in } \\
\text { the group }\end{array}$ & $4(4,4)$ & $4(4,4)$ & $4(4,4)$ \\
\hline $\begin{array}{l}\text { 9. In the group, some contradictory beliefs on information concerning the } \\
\text { learning content were present }\end{array}$ & $4(4,4)$ & $4(4,4)$ & $4(3,4)$ \\
\hline 10. One or more group members was/were contradicted by the others & $4(3,4)$ & $4(3,4)$ & $3.5(2,4)$ \\
\hline $\begin{array}{l}\text { 11. When someone contradicted a group member, that person stated a } \\
\text { counter-argument }\end{array}$ & $4(3,4)$ & $4(3,4)$ & $3(2,4)$ \\
\hline
\end{tabular}

Table 2: Student responses for various questions asked during focus group discussion

\begin{tabular}{|c|c|c|c|c|}
\hline \multicolumn{2}{|c|}{ Driving factors for interaction } & \multicolumn{2}{|c|}{ Hindering factors for interaction } & \multirow{2}{*}{$\begin{array}{l}\text { Suggestions to } \\
\text { improve } \\
\text { interaction }\end{array}$} \\
\hline Student related & Facultyrelated & Student related & Faculty related & \\
\hline $\begin{array}{ll}\text { 1. } & \text { Prior } \\
& \text { knowledge/ } \\
& \text { experience } \\
\text { 2. } & \text { Motivation } \\
\text { 3. } & \text { Confidence } \\
\text { 4. } & \text { Familiarity } \\
& \text { among peers } \\
\text { 5. } & \text { Effective } \\
& \text { leader }\end{array}$ & $\begin{array}{ll}\text { 1. } & \text { Guidance } \\
\text { 2. Clues } \\
\text { 3. Encouragement } \\
\text { 4. Non } \\
\text { interference } \\
\text { 5. Assessment }\end{array}$ & $\begin{array}{ll}\text { 1. } & \text { No prior } \\
\text { knowledge } \\
\text { 2. } & \text { Fear of giving } \\
& \text { wrong } \\
\text { information } \\
\text { 3. Language barriers } \\
\text { 4. Talkative group } \\
\text { members }\end{array}$ & $\begin{array}{ll}\text { 1. } & \text { Difficult case } \\
\text { scenarios } \\
\text { 2. Tutor's sarcasm }\end{array}$ & 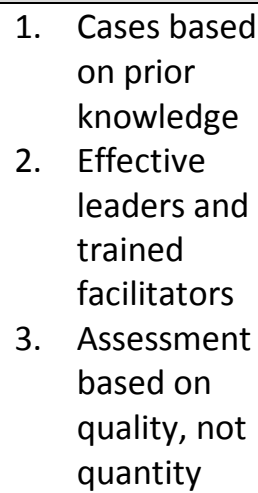 \\
\hline
\end{tabular}




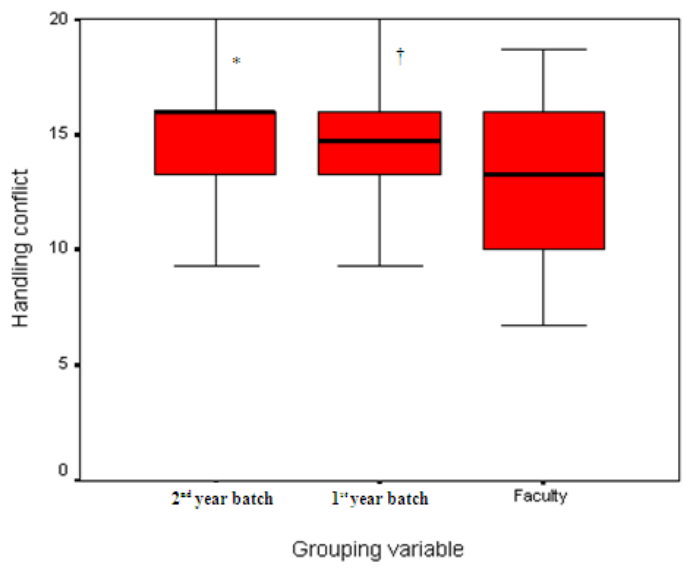

${ }^{*} \mathrm{p}=0.003,2^{\text {nd }}$ year batch vs faculty; $\dagger \mathrm{p}=0.004,1^{\text {st }}$ year batch vs faculty

Figure 2: Comparison of cumulative average score (median and inter quartile range) of handling conflict factor between students' and faculty groups.

\section{Discussion}

The questionnaire used in this study had 11 items belonging to 3 different factors: exploratory questions, cumulative reasoning and handling conflicts [13]. These three factors were derived from three types of talk and thought in groups during PBL process, as described by Mercer, 1995, 1996 [14, 15] and three types of interaction as specified by Van Boxtel, 2000 [3]. Exploratory talk occurs when group members engage critically but constructively with each other's ideas. Exploratory talk has been found to be most effective for learning through collaborative activity. In cumulative talk, speakers build positively but uncritically on what the others have said. In this type of talk, students construct a 'common knowledge' by accumulation [15].

The present study explored students' and faculty perceptions of the occurrence of learningoriented group interaction during brainstorming session of PBL. The study also investigated discrepancies in the perception between student groups and faculty in order to indicate where the improvement was desirable. The median score for the occurrence of all interactions was more than 3 (Table 1) which indicates that at MMMC, students construct knowledge through elaboration during PBL session. Moreover, at our institute, the quality of student interaction during brainstorming session of PBL could be considered as reasonable which is supported by similar study done by Visschers-Pleijers et al, 2005 [13]. The average score of factors did not differ significantly between student groups which mean that students' understanding / expectations regarding group interaction did not change when they proceeded from $1^{\text {st }}$ year to $2^{\text {nd }}$ year of the course. Highest score of cumulative reasoning factor in $1^{\text {st }}$ year students group compared to $2^{\text {nd }}$ year group indicates that the emphasis in PBL sessions shifts from problem solving to learning from the process of $\mathrm{PBL}$ when students proceed to $2^{\text {nd }}$ year.

Occurrence of productive conflicts and open arguments were more in $2^{\text {nd }}$ year students compared to $1^{\text {st }}$ year which was supported by qualitative data in which $2^{\text {nd }}$ year students opined that familiarity among peers and less fear of judgment drives interaction during PBL sessions (Table 2).

Though the results showed that understanding regarding the process and expectations of PBL between MMMC faculty and students were similar, significant differences were observed between faculty and students groups on items related to critical questions (Item 2) and counterarguments (Item 11) (Table 1). This difference showed that faculty expectations regarding asking critical questions and counter-arguments were more than students' perceptions and faculty expectations were not clear to the students. Hence at MMMC, during PBL training, more emphasis has to be given to interactions that occur during PBL process. Thus evaluation of student interactions during $\mathrm{PBL}$ can be used for quality control of $\mathrm{PBL}$ process and to give feedback to students.

According to students' perspectives the main hindering factor for appropriate group discussion was the quality of case scenarios. Students felt that adequate discussion did not take place as case scenarios were not designed based on their prior knowledge (Table 2). Students actively construct explanatory models based on prior knowledge, which in turn facilitate the processing and comprehension of new 
information [4]. Therefore, at MMMC, there is a need to revise or design PBL cases based on students' prior knowledge. In this regard, a preliminary work was done at MMMC to find out students' perceptions regarding an ideal PBL case [16] which was considered while designing case scenarios.

The present study has some limitations. Lack of awareness of an ideal productive PBL interaction in the study population might have affected the study result. Moreover, a clear quality of students' interactions could have been assessed using observational method instead of perceptions. The second limitation is that, the tutors' score took an account of students' group interactions during all brainstorming sessions of that academic year, whereas students' scores included only the particular brain-storming session in which students were asked to respond. So students' score might have been influenced by case scenarios, tutor and by group members as at MMMC reshuffling of students takes place before each PBL sessions.

This study looked into the learning process, more specifically, learning through group interaction during PBL. At MMMC, only 30\% of the curriculum is covered through PBL. Hence this study looked into only $30 \%$ of the curriculum. The impact of $70 \%$ of traditional curriculum on PBL process was not explored in this study. It seems worthwhile to study the role of case scenarios in promoting quality interactions. Measured quality of interactions needs to be correlated with outcomes of PBL to see whether the perceived quality interaction is really the expected quality interaction that drives learning during PBL sessions. The students and faculty perceptions could be compared with tutorial group productivity. The quality of group interactions could be assessed during reporting phase of PBL session also. The tutor role on quality of interactions could also be explored.

\section{Conclusion}

Students' understanding / expectations regarding PBL interaction did not change much during their course. Faculty expectations regarding asking critical questions and counter argument are different from the students' understanding of PBL interaction. This study helped us to understand and bridge the gap between faculty expectations and students' performance by orientating students regarding an ideal / model PBL interaction. Furthermore, designing the PBL cases based on prior knowledge may bring out a productive group discussion during $\mathrm{PBL}$ sessions.

\section{Acknowledgement}

The authors thank faculty and students of Melaka Manipal Medical College for participating in the study. We are grateful to Visschers-Pleijers et al (2005) for permitting us to use the questionnaire. We also would like to thank Dr.Reem Rachel Abraham (Associate Professor, Dept. of Physiology) for helpful comments on aspects of this project.

\section{Reference}

1. Biggs JB. Teaching for quality learning at university $2^{\text {nd }}$ ed. Buckingham: Open University Press. 2003

2. DeGrave, WS, Boshuizen HPA, Schmidt HG. Problem-based learning: Cognitive and metacognitive processes during problem analysis. Instructional Science 1996:24:32141.

3. Van Boxtel C. Collaborative Concept Learning: Collaborative learning tasks, student interaction, and the learning of physics concepts. [Unpublished $\mathrm{PhD}$ thesis]. Utrecht: Utrecht University. 2000 (cross reference)

4. Schmidt HG, De Volder ML, De Grave WS, Moust JHC, Patel VL. Explanatory models in the processing of science text: The role of prior knowledge activation through smallgroup discussion. J Educ Psychol 1989:81:610-19.

5. Regehr G, Norman GR. Issues in cognitive psychology: implications for professional education. Acad Med 1996:71:988-1001.

6. De Grave WS, Schmidt HG, Boshuizen HPA. Effects of problem-based discussion on studying a subsequent text: A randomized trial among first-year medical students. Instructional Science 2001;29:33-44.

7. Johnson DW, Johnson RT, Smith KA. Active learning: Cooperation in the college 
classroom. Edina: Interaction Book Company. 1991

8. Norman GR, Schmidt HG. The Psychological Basis of Problem-based Learning: A Review of the Evidence. Acad Med 1992;67:557-565.

9. Dolmans DHJM, Wolfhagen HAP, Van der Vleuten CPM. Motivational and cognitive processes influencing tutorial groups. Acad Med 1998;73: S22-S24.

10. Das Carlo M, Swadi H, Mpofu D. Medical Student Perceptions of Factors Affecting Productivity of Problem-Based Learning Tutorial Groups: Does Culture Influence the Outcome? Teach Learn Med 2003;15:59-64.

11. De Grave WS, Dolmans DHJM, Van der Vleuten CPM. Student Perspectives on Critical Incidents in the Tutorial Group. Adv Health Sci Educ 2002;7:201-209.

12. Dolmans DHJM, Wolfhagen HAP, Van der Vleuten CPM, Wijnen WHFW. Solving problems with group work in problem-based learning: hold on to the philosophy. Med Educ 2001;35: 884-889.

13. Visschers-Pleijers JSFA, Dolmans HJMD, Wolfhagena HAPI, Van der Vleuten PMC. Development and validation of a questionnaire to identify learning-oriented group interactions in PBL. Med Teach 2005;27:375-381.

14. Mercer N. The guided construction of knowledge: Talk amongst teachers and learners. Clevedon: Multilingual Matters. 1995.

15. Mercer N. (1996). The quality of talk in children's collaborative activity in the classroom. Learning and Instruction 1996:6:359-377.

16. Devi V, Abraham RR, Pallath V, Mohammed CA. Students' perspectives regarding an ideal PBL case. Med Teach 2011;33: 169-170 